University of Nebraska - Lincoln

DigitalCommons@University of Nebraska - Lincoln

2004

\title{
Matrix Isolation Infrared Spectroscopic and Theoretical Study of the Interaction of Water with Dimethyl Methylphosphonate
}

Bruce S. Ault

Department of Chemistry, UniVersity of Cincinnati, P.O. Box 210172, Cincinnati, Ohio

Alex Balboa

Edgewood Chemical Biological Center, Aberdeen ProVing Ground, Maryland

David Tevault

Edgewood Chemical Biological Center, Aberdeen ProVing Ground, Maryland

Margaret Hurley

Weapons and Materials Research Directorate, U.S. Army Research Laboratory, Aberdeen ProVing Ground, Maryland

Follow this and additional works at: https://digitalcommons.unl.edu/usarmyresearch

Part of the Operations Research, Systems Engineering and Industrial Engineering Commons

Ault, Bruce S.; Balboa, Alex; Tevault, David; and Hurley, Margaret, "Matrix Isolation Infrared Spectroscopic and Theoretical Study of the Interaction of Water with Dimethyl Methylphosphonate" (2004). US Army Research. 28.

https://digitalcommons.unl.edu/usarmyresearch/28

This Article is brought to you for free and open access by the U.S. Department of Defense at DigitalCommons@University of Nebraska - Lincoln. It has been accepted for inclusion in US Army Research by an authorized administrator of DigitalCommons@University of Nebraska - Lincoln. 


\title{
Matrix Isolation Infrared Spectroscopic and Theoretical Study of the Interaction of Water with Dimethyl Methylphosphonate
}

\author{
Bruce S. Ault* \\ Department of Chemistry, University of Cincinnati, P.O. Box 210172, Cincinnati, Ohio 45221
}

\author{
Alex Balboa and David Tevault \\ Edgewood Chemical Biological Center, Aberdeen Proving Ground, Maryland 21010-5424
}

\author{
Margaret Hurley \\ Weapons and Materials Research Directorate, U.S. Army Research Laboratory, \\ Aberdeen Proving Ground, Maryland 21005
}

Received: August 3, 2004; In Final Form: September 12, 2004

\begin{abstract}
Matrix isolation infrared spectroscopy has been combined with theoretical calculations for the characterization of the 1:1 hydrogen-bonded complex between $\mathrm{H}_{2} \mathrm{O}$ and dimethyl methylphosphonate (DMMP). The symmetric $\mathrm{O}-\mathrm{H}$ stretching mode was observed to shift $203 \mathrm{~cm}^{-1}$ to lower energy upon hydrogen bond formation, while a $32 \mathrm{~cm}^{-1}$ blue shift was noted for the $\mathrm{H}-\mathrm{O}-\mathrm{H}$ bending mode of the $\mathrm{H}_{2} \mathrm{O}$ subunit in the complex. These values compare extremely well with the (unscaled) shifts of -203 and $+32 \mathrm{~cm}^{-1}$, respectively, that were calculated theoretically at the MP2/6-31+G** level. Additional perturbed modes of the DMMP subunit were observed, shifted relative to the parent band position. The greatest perturbation was to the $\mathrm{P}=\mathrm{O}$ stretching mode near $1270 \mathrm{~cm}^{-1}$, where a shift of $-17 \mathrm{~cm}^{-1}$ was observed $\left(-21 \mathrm{~cm}^{-1}\right.$ calculated theoretically). This suggests that the site of hydrogen bonding in the complex is at the $\mathrm{P}=\mathrm{O}$ group, in agreement with theoretical calculations. The binding energy $\Delta E^{\circ}$ for the $1: 1$ complex was calculated to be $-7.7 \mathrm{kcal} / \mathrm{mol}$.
\end{abstract}

\section{Introduction}

The volatility of solution and mixture components is required to perform optimum separations by distillation and is described theoretically by Raoult's law. Deviations from Raoult's law are commonly observed in either direction. The volatility of chemicals, including toxic industrial materials and chemical warfare agents, in ambient (humid) air is an important consideration toward understanding their behavior following accidental or intentional release to the environment. Recent work performed at the U.S. Army Edgewood Chemical Biological Center (ECBC) has demonstrated that the volatility of the nerve agent simulant dimethyl methylphosphonate (DMMP) is significantly suppressed, i.e., as much as $40 \%$ greater suppression than predicted by Raoult's law, by the presence of humidity in the air carrier. ${ }^{1,2}$

Matrix isolation studies have been carried out on the DMMP and water system to further elucidate the behavior of this simulant under humid conditions. The matrix isolation technique $^{3-5}$ was developed for the isolation, stabilization, and spectroscopic characterization of reactive or short-lived species in inert cryogenic matrices. Species that have been studied in this manner include radicals, ions, and weakly bound molecular complexes. The utility of matrix isolation in combination with infrared spectroscopy to isolate and characterize 1:1 hydrogenbonded complexes between proton donors and proton acceptors is well established. ${ }^{6}$ In particular, complexes involving $\mathrm{H}_{2} \mathrm{O}$ serving as either a proton donor or a proton acceptor have been studied $^{7-9}$ in recent years. Consequently, to better understand the interaction between DMMP and water that leads to the suppression of volatility, matrix isolation experiments were undertaken.

In conjunction with the above experimental study, theoretical calculations have also been performed on the DMMP: $\mathrm{H}_{2} \mathrm{O}$ complex. Computational chemistry is emerging as a powerful tool in the analysis of the nature and properties of hydrogenbonded systems. The use of density functional theory and ab initio computational chemistry to investigate the extent of hydrogen bonding can supplement infrared spectroscopic measurements and provide detailed atomistic level understanding of these interactions. This has been demonstrated by previous combined matrix isolation/theoretical studies of hydrogenbonded complexes such as the $\mathrm{H}_{2} \mathrm{O}_{2}: \mathrm{HF}$ and $\mathrm{H}_{2} \mathrm{O}_{2}: \mathrm{PH}_{3}$ systems..$^{10-13}$ The present study provides evidence of hydrogenbonded complexes of water and DMMP in the gas phase. In this paper, the structural, energetic, and spectral properties of these complexes will be presented and discussed in an experimental and theoretical perspective.

\section{Experimental Details}

The experiments in this study were carried out with matrix isolation equipment that has been described elsewhere, ${ }^{14}$ with modification for the generation and deposition of DMMP. DMMP was introduced into the vacuum system by placing a few drops of the neat liquid in a small stainless steel sidearm, connected to the deposition line through a needle valve to an Ultratorr tee. After a brief pumping time, the needle valve was opened slightly, allowing a fraction of the vapor pressure of DMMP at room temperature to be entrained in flowing argon, carried to the cold window, and deposited. $\mathrm{H}_{2} \mathrm{O}$ (distilled) and 
$\mathrm{H}_{2}{ }^{18} \mathrm{O}\left(99 \%{ }^{18} \mathrm{O}\right)$ (Cambridge Isotope Laboratory) were introduced by placing about $1 \mathrm{~mL}$ of the liquid into a glass finger attached to a vacuum manifold and were purified by repeated freeze-pump-thaw cycles at $77 \mathrm{~K}$. The room temperature vapor pressure was then used to prepare the sample. Argon (Wright Brothers, 99.99\%) was used as the matrix gas in all experiments and was used without purification.

All matrix samples were deposited in the twin jet mode. Here, the two gas samples (Ar/DMMP and $\mathrm{Ar} / \mathrm{H}_{2} \mathrm{O}$ ) were deposited from separate nozzles onto the $14 \mathrm{~K}$ cold window, allowing for only a very brief mixing time prior to matrix deposition. Several of these matrices were subsequently warmed to 33-39 $\mathrm{K}$ to permit limited diffusion and then recooled to $14 \mathrm{~K}$ and additional spectra recorded. In these experiments, matrices were deposited at the rate of $2 \mathrm{mmol} / \mathrm{h}$ from each sample manifold onto the cold window. Final spectra were recorded on a PerkinElmer Spectrum One Fourier transform infrared spectrometer at $1 \mathrm{~cm}^{-1}$ resolution.

\section{Method of Calculation}

DMMP and $\mathrm{H}_{2} \mathrm{O}$, as well as the 1:1 DMMP: $\mathrm{H}_{2} \mathrm{O}$ complex, were fully optimized at the B3LYP/6-31G**, MP2/6-31G**, and $\mathrm{MP} 2 / 6-31+\mathrm{G}^{* *}$ levels. All DFT calculations used an ultrafine grid. All geometry optimizations were performed with tight convergence criteria. Harmonic vibrational frequencies were computed to confirm that the optimized structures are equilibrium structures, and for comparison with experiment. All calculations were performed ${ }^{15}$ with Gaussian G03.

\section{Experimental Results}

Before co-deposition experiments were run, blank spectra of $\mathrm{H}_{2} \mathrm{O}$ and DMMP in solid argon were obtained in separate experiments. These spectra agree with published data ${ }^{16-18}$ and spectra previously obtained in this laboratory. While some water dimer was present in all experiments and was relatively more intense in the more concentrated experiments, the concentrations were kept low so that the monomer was the dominant species present in all $\mathrm{H}_{2} \mathrm{O}$ blank and co-deposition experiments. Due to adsorption of $\mathrm{H}_{2} \mathrm{O}$ vapor onto the walls of the sample manifold and the deposition line, determination of the precise concentration of the $\mathrm{Ar} / \mathrm{H}_{2} \mathrm{O}$ sample was impossible. Rather, conditions were employed which minimized the concentration of the water dimer, while maintaining a sufficient monomer concentration.

$\mathbf{H}_{2} \mathbf{O}+$ DMMP: Since trace amounts of water are always present in matrix experiments, even the blank experiments described above contained small amounts of water. As such, a quite weak band was noted at $3436 \mathrm{~cm}^{-1}$ in these experiments. When an experiment was then conducted in which a sample of Ar/DMMP was co-deposited with a prepared sample of $\mathrm{Ar} / \mathrm{H}_{2} \mathrm{O}$, the band at $3436 \mathrm{~cm}^{-1}$ was observed to grow substantially as is shown in Figure 1. A number of additional features were seen elsewhere in the spectrum, the most intense of which was a doublet at $1245,1253 \mathrm{~cm}^{-1}$, which $17 \mathrm{~cm}^{-1}$ to the red of a parent DMMP doublet at 1262, $1270 \mathrm{~cm}^{-1}$, as shown in Figure 2. New bands were also seen at 468, 799, 827, 900, 927, and $1633 \mathrm{~cm}^{-1}$, near parent bands of DMMP at 472, 792, 820, 895, and $917 \mathrm{~cm}^{-1}$, and $\mathrm{H}_{2} \mathrm{O}$ at $1601 \mathrm{~cm}^{-1}$. When this matrix was subsequently annealed at $34 \mathrm{~K}$, recooled, and an additional spectrum recorded, all of the above product bands were observed to grow substantially (nearly a $100 \%$ increase). Moreover, these bands all maintained a constant intensity ratio with respect to one another, to the degree that intensities could be measured

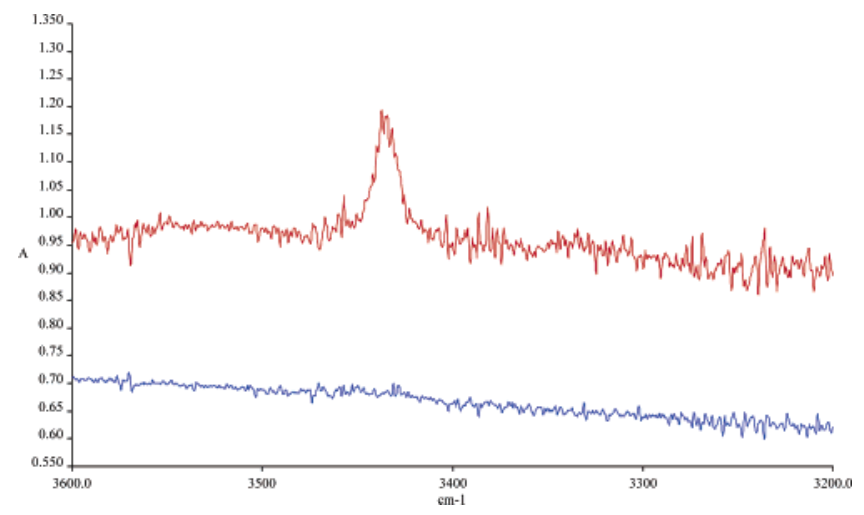

Figure 1. A comparison of the spectrum arising from the co-deposition of a sample of $\mathrm{Ar} / \mathrm{H}_{2} \mathrm{O}$ with a sample of $\mathrm{Ar} / \mathrm{DMMP}$ at $14 \mathrm{~K}$ (upper trace) compared to a blank spectrum of DMMP without added $\mathrm{H}_{2} \mathrm{O}$ (lower trace). The product band at $3436 \mathrm{~cm}^{-1}$ shown in the upper trace is assigned to the symmetric $\mathrm{O}-\mathrm{H}$ stretching mode of $\mathrm{H}_{2} \mathrm{O}$ in a $1: 1$ complex with DMMP. The shift of $-203 \mathrm{~cm}^{-1}$ from parent $\mathrm{H}_{2} \mathrm{O}$ is indicative of a hydrogen bonding interaction between DMMP and water. This interaction is consistent with the negative deviation from ideal vapor phase behavior.

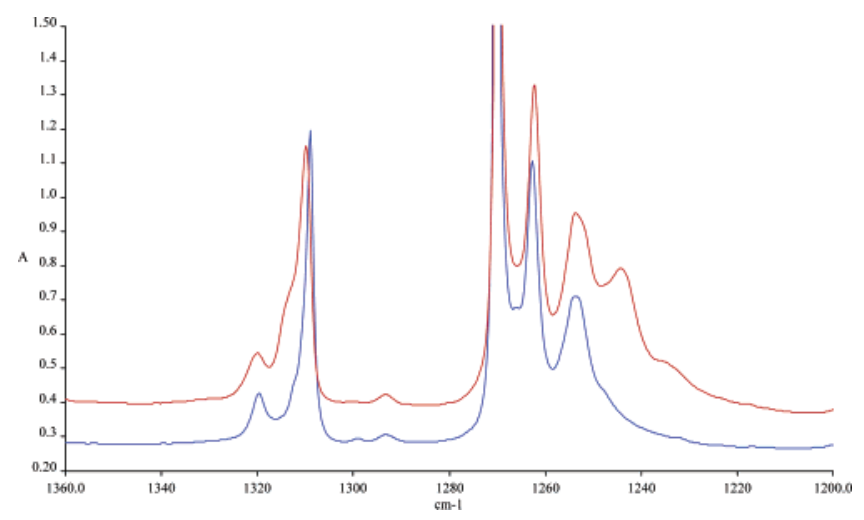

Figure 2. A comparison of the spectrum arising from the co-deposition of a sample of $\mathrm{Ar} / \mathrm{H}_{2} \mathrm{O}$ with a sample of $\mathrm{Ar} / \mathrm{DMMP}$ at $14 \mathrm{~K}$ (upper trace) compared to a blank spectrum of DMMP without added $\mathrm{H}_{2} \mathrm{O}$ (lower trace). The product band at $1249 \mathrm{~cm}^{-1}$ shown in the upper trace is assigned to the $\mathrm{P}=\mathrm{O}$ stretching mode of DMMP in the 1:1 complex and indicates that the $\mathrm{P}=\mathrm{O}$ bond is the site of hydrogen bond formation in the complex.

accurately for those bands that were close to, and partially overlapping the parent bands.

Ten additional experiments were conducted in which DMMP and $\mathrm{H}_{2} \mathrm{O}$ were deposited into argon matrices. In these experiments, the concentrations of the two reagents were varied, from quite dilute to relatively concentrated, and the relative concentrations were varied as well. In all of these experiments, similar product bands were observed. Specifically, the band at 3436 $\mathrm{cm}^{-1}$ was present, with an intensity that qualitatively correlated with the concentrations of the two reagents (e.g., when the concentration of DMMP increased, the intensity of the 3436$\mathrm{cm}^{-1}$ band increased by approximately the same factor, and likewise with $\mathrm{H}_{2} \mathrm{O}$ ). The additional product bands listed above were seen as well, with a comparable variation in intensity with parent concentration. Each of these matrices was subsequently annealed to between 34 and $38 \mathrm{~K}$, recooled, and additional spectra recorded. In each experiment, the product bands grew substantially upon annealing, while maintaining a relatively constant intensity ratio with respect to one another.

As described by previous researchers, ${ }^{16,17}$ in some experiments parent water was seen to undergo hindered rotation in the argon matrix, while in other experiments only rotationless parent water was observed. This has been attributed to subtle 
TABLE 1: Product Bands $\left(\mathrm{cm}^{-1}\right)$ Arising from the Co-deposition of DMMP with $\mathrm{H}_{2} \mathrm{O}$ and $\mathrm{H}_{2}{ }^{18} \mathrm{O}$ into Argon Matrices

\begin{tabular}{lcccccc}
\hline parent & parent band & DMMP: $\mathrm{H}_{2}{ }^{16} \mathrm{O}$ & shift & DMMP: $\mathrm{H}_{2}{ }^{18} \mathrm{O}$ & ${ }^{18} \mathrm{O}-{ }^{16} \mathrm{O}$ shift & assignment \\
\hline DMMP & 472 & 468 & -4 & 799 & 0 & $\mathrm{PO}_{2}$ bend \\
DMMP & 792 & 799 & 7 & 7 & 827 & 0 \\
DMMP & 820 & 827 & 5 & 900 & 0 & $\mathrm{P}-\mathrm{O}$ stretch \\
DMMP & 895 & 900 & 10 & 927 & 0 & $\mathrm{P}-\mathrm{O}$ stretch \\
DMMP & 917 & 927 & -17 & 1248 & -1 & $\mathrm{CH}_{3}$ rock \\
DMMP & 1266 & 1249 & 32 & & $\mathrm{P}=\mathrm{O}$ stretch \\
$\mathrm{H}_{2} \mathrm{O}$ & 1601 & 1633 & $-189,-211^{a}$ & 3419,3440 & $-9,-10$ & $\mathrm{H}$ bend \\
$\mathrm{H}_{2} \mathrm{O}$ & 3639 & 3428,3450 & & & $\mathrm{O}-\mathrm{H}$ stretch
\end{tabular}

${ }^{a}$ For matrices with nonrotating water (see text), the shift was $-203 \mathrm{~cm}^{-1}$.

changes in the structure of the argon matrix due to the presence of the dopant molecules. When rotating water was seen, the $3436-\mathrm{cm}^{-1}$ band appeared as a doublet at 3428 and $3450 \mathrm{~cm}^{-1}$, while when nonrotating water was observed, the product band was seen at $3436 \mathrm{~cm}^{-1}$. While these observations suggest slight changes in the argon matrix structure from one experiment to the next, they do not affect in any way the overall conclusions of this study.

$\mathbf{H}_{2}{ }^{18} \mathbf{O}+$ DMMP: Samples of Ar/DMMP were co-deposited with samples of $\mathrm{Ar} / \mathrm{H}_{2}{ }^{18} \mathrm{O}$ in a series of experiments, again varying the concentrations of the two reagents in a systematic way. In these experiments, rotating parent water was observed, and the product band in the $3400-\mathrm{cm}^{-1}$ region appeared as a doublet, but shifted relative to the experiments with normal isotopic water. Specifically, this doublet was observed at 3419, $3440 \mathrm{~cm}^{-1}$, approximately $10 \mathrm{~cm}^{-1}$ to the red of the normal isotope. Additional product bands were seen elsewhere in the spectrum, at $468,799,827,899,927$, and $1248 \mathrm{~cm}^{-1}$. These all were within $1 \mathrm{~cm}^{-1}$ of the band position with naturally abundant isotopic water. Unfortunately, the region near 1600 $\mathrm{cm}^{-1}$ was so congested with parent bands of $\mathrm{H}_{2}{ }^{18} \mathrm{O}$ and residual $\mathrm{H}_{2}{ }^{16} \mathrm{O}$ that no product band could be observed in this region [note: while $\mathrm{H}_{2} \mathrm{O}$ in natural isotopic abundance contains a mixture of oxygen isotopes, in these experiments only $\mathrm{H}_{2}{ }^{16} \mathrm{O}$ is detectable due to low abundances of the remaining oxygen isotopes]. The next-most-abundant isotope is ${ }^{18} \mathrm{O}$, which is present as $0.20 \%$ naturally. Consequently, water in natural abundance will be referred to as $\mathrm{H}_{2}{ }^{16} \mathrm{O}$. All of these product bands grew substantially upon annealing, just as was observed for $\mathrm{H}_{2}{ }^{16} \mathrm{O}$. Further, the intensity of each product band in the series of experiments varied directly with the concentrations of the two precursors, as described above. All of the above product bands are listed in Table 1.

\section{Results of Calculations}

DMMP has been studied previously at the Hartree-Fock and MP2 level. ${ }^{19,20}$ The potential energy landscape of this compound was demonstrated to be complicated by the existence of several nearly isoenergetic conformers within a $\sim 3 \mathrm{kcal} / \mathrm{mol}$ range. The lowest energy conformer (Conformer I) has an asymmetric structure with inequivalent methoxy side chains $\left(\mathrm{CH}_{3}-\mathrm{P}-\mathrm{O}-\right.$ $\mathrm{CH}_{3}$ dihedral values approximately in the $175^{\circ}$ and $103^{\circ}$ range). The next highest conformer (Conformer II) is a symmetric configuration of the methoxy groups (both dihedrals have a magnitude of approximately $159.7^{\circ}$ ) and is $\sim 0.21 \mathrm{kcal} / \mathrm{mol}$ higher in energy. Although these calculations are in no way performed to chemical accuracy, the relative energetics show excellent agreement with previous results at HF/6-31G* $(0.09$ $\mathrm{kcal} / \mathrm{mol})$ and $\mathrm{MP} 2 / 6-311++\mathrm{G}^{* *}(0.48 \mathrm{kcal} / \mathrm{mol})$ and confirm that the correct trend of conformers is found. These are the only two conformers currently under study.

Upon complexation with water, a hydrogen bond formed between water and the DMMP $\mathrm{P}=\mathrm{O}$ group is predicted (Figure

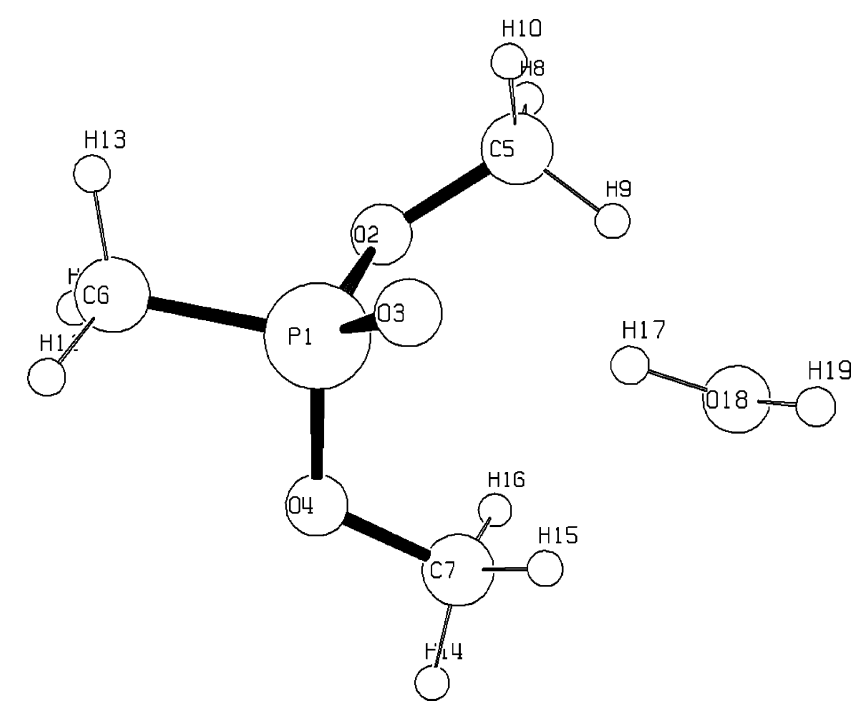

Figure 3. Calculated structure of DMMP: $\mathrm{H}_{2} \mathrm{O}$ obtained at MP2/6$31+\mathrm{G}^{* *}$. The orientation of water toward the $\mathrm{P}=\mathrm{O}$ bond is clearly shown.

3). The structure of the final DMMP: $\mathrm{H}_{2} \mathrm{O}$ complex is identical regardless of the initial DMMP conformation (I or II). The binding energy $\Delta E^{\circ}$, defined as $E_{\mathrm{DMMP}_{\mathrm{H}} \mathrm{O}}-\left(E_{\mathrm{DMMP}}+E_{\mathrm{H}_{2} \mathrm{O}}\right)$, is calculated as $-7.7 \mathrm{kcal} / \mathrm{mol}$ at the $\mathrm{MP} 2 / 6-31+\mathrm{G}^{* *}$ level, including the counterpoise correction. We limit ourselves to the 1:1 DMMP: $\mathrm{H}_{2} \mathrm{O}$ system, although it is interesting to note that in ongoing work involving more solvent (including DMMP solvated in 9-water and 24-water clusters), as well as in other theoretical studies ${ }^{21}$ the $\mathrm{P}=\mathrm{O}$ group appears to be capable of forming hydrogen bonds with multiple water molecules.

Table 2 presents a partial listing of the peak locations related to the $\mathrm{P}=\mathrm{O}$ stretch, $\mathrm{H}-\mathrm{O}-\mathrm{H}$ bend, and $\mathrm{O}-\mathrm{H}$ symmetric stretch, for DMMP, water, and the DMMP: $\mathrm{H}_{2} \mathrm{O}$ complex. Theoretical results are presented at the MP2/6-31+G**, MP2/6-31G**, and B3LYP/6-31G** levels. Frequencies were also calculated for the DMMP: $\mathrm{H}_{2}{ }^{18} \mathrm{O}$ complex isotope, for comparison to experiment. No scaling factors are used in the tabulated frequency values, although scaling values for the methods and basis sets chosen are documented.

\section{Discussion}

As reported above, a number of new infrared absorptions were noted when samples of $\mathrm{Ar} / \mathrm{H}_{2} \mathrm{O}$ were co-deposited with samples of Ar/DMMP onto a $14 \mathrm{~K}$ cold surface. These new absorptions require the presence of both reagents, suggesting that they are interacting or reacting in some manner. The fact that these bands grew upon annealing the matrix to $31 \mathrm{~K}$ requires that the reaction or interaction of $\mathrm{H}_{2} \mathrm{O}$ with DMMP have essentially no activation barrier. This is typical of hydrogen bond formation, but not of chemical reaction. Further, while several new bands were observed, no frequency shift was observed for a number of bands 
TABLE 2: Calculated Product Bands $\left(\mathrm{cm}^{-1}\right)$ of DMMP(I) with $\mathrm{H}_{2} \mathrm{O}$ and $\mathrm{H}_{2}{ }^{18} \mathrm{O}$ at $\mathrm{MP2} / 6-31+\mathrm{G}^{* *}, \mathrm{B3LYP} / 6-31 \mathrm{G}^{* *}$, and MP2/6-31G**

\begin{tabular}{|c|c|c|c|c|c|c|}
\hline parent & $\begin{array}{c}\text { parent } \\
\text { band }\end{array}$ & $\begin{array}{c}\text { DMMP: } \\
\mathrm{H}_{2}{ }^{16} \mathrm{O}\end{array}$ & $\begin{array}{l}\text { calcd } \\
\text { shift }\end{array}$ & $\begin{array}{c}\text { DMMP: } \\
\mathrm{H}_{2}{ }^{18} \mathrm{O}\end{array}$ & $\begin{array}{c}{ }^{18} \mathrm{O}-{ }^{16} \mathrm{O} \\
\text { shift }\end{array}$ & assignment \\
\hline \multicolumn{7}{|c|}{ (a) MP2/6-31+G** } \\
\hline DMMP & 466 & 455 & -11 & 455 & 0 & $\mathrm{PO}_{2}$ bend \\
\hline DMMP & 788 & 792 & 4 & 792 & 0 & $\mathrm{P}-\mathrm{O}$ stretch \\
\hline DMMP & 832 & 838 & 6 & 838 & 0 & $\mathrm{P}-\mathrm{O}$ stretch \\
\hline DMMP & 940 & 944 & 4 & 944 & 0 & $\mathrm{CH}_{3}$ rock \\
\hline DMMP & 956 & 962 & 10 & 962 & 0 & $\mathrm{CH}_{3}$ rock \\
\hline DMMP & 1260 & 1239 & -21 & 1239 & 0 & $\mathrm{P}=\mathrm{O}$ stretch \\
\hline $\mathrm{H}_{2} \mathrm{O}$ & 1623 & 1655 & 32 & 1649 & -6 & $\mathrm{H}_{2} \mathrm{O}$ bend \\
\hline $\mathrm{H}_{2} \mathrm{O}$ & 3866 & 3663 & -203 & 3653 & -10 & $\mathrm{O}-\mathrm{H}$ stretch \\
\hline \multicolumn{7}{|c|}{ (b) B3LYP/6-31G** } \\
\hline DMMP & 468 & 460 & -8 & 460 & 0 & $\mathrm{PO}_{2}$ bend \\
\hline DMMP & 783 & 787 & 4 & 787 & 0 & $\mathrm{P}-\mathrm{O}$ stretch \\
\hline DMMP & 808 & 816 & 8 & 816 & 0 & $\mathrm{P}-\mathrm{O}$ stretch \\
\hline DMMP & 925 & 929 & 4 & 929 & 0 & $\mathrm{CH}_{3}$ rock \\
\hline DMMP & 943 & 948 & 5 & 948 & 0 & $\mathrm{CH}_{3}$ rock \\
\hline DMMP & 1273 & 1243 & -30 & 1243 & 0 & $\mathrm{P}=\mathrm{O}$ stretch \\
\hline $\mathrm{H}_{2} \mathrm{O}$ & 1665 & 1688 & 23 & 1681 & -7 & $\mathrm{H}_{2} \mathrm{O}$ bend \\
\hline $\mathrm{H}_{2} \mathrm{O}$ & 3800 & 3584 & -216 & 3574 & -10 & $\mathrm{O}-\mathrm{H}$ stretch \\
\hline \multicolumn{7}{|c|}{ (c) MP2/6-31G** } \\
\hline DMMP & 474 & 466 & -8 & 466 & 0 & $\mathrm{PO}_{2}$ bend \\
\hline DMMP & 805 & 807 & 2 & 807 & 0 & $\mathrm{P}-\mathrm{O}$ stretch \\
\hline DMMP & 840 & 848 & 8 & 848 & 0 & $\mathrm{P}-\mathrm{O}$ stretch \\
\hline DMMP & 951 & 955 & 4 & 955 & 0 & $\mathrm{CH}_{3}$ rock \\
\hline DMMP & 967 & 973 & 6 & 973 & 0 & $\mathrm{CH}_{3}$ rock \\
\hline DMMP & 1292 & 1266 & -26 & 1266 & 0 & $\mathrm{P}=\mathrm{O}$ stretch \\
\hline $\mathrm{H}_{2} \mathrm{O}$ & 1682 & 1713 & 31 & 1707 & -6 & $\mathrm{H}_{2} \mathrm{O}$ bend \\
\hline $\mathrm{H}_{2} \mathrm{O}$ & 3892 & 3720 & -172 & 3709 & -11 & $\mathrm{O}-\mathrm{H}$ stretch \\
\hline
\end{tabular}

of DMMP. This also argues against a distinct chemical reaction where bonds are broken and new bonds formed. This would lead to a completely different spectrum, while the actual spectrum resembled the two reagents with shifting of only a few vibrational modes. This behavior is entirely consistent with the results observed at ECBC previously ${ }^{1}$ and is characteristic of hydrogen bond formation, where the two subunits in the hydrogen bond (proton donor and proton acceptor) are perturbed by the interaction and vibrations associated with the hydrogenbonding region are shifted. ${ }^{22}$ At the same time, bands not directly associated with the hydrogen-bonding region (for example, the methyl group vibrations) are not perturbed and hence do not shift.

Hydrogen bonding is indicated as well by the fact that the most intense product band was observed near $3436 \mathrm{~cm}^{-1}$. This is a spectral region associated with $\mathrm{O}-\mathrm{H}$ stretching motions, yet is shifted several hundred wavenumbers to lower energy of parent $\mathrm{H}_{2} \mathrm{O}$. The most characteristic infrared signatures ${ }^{22}$ of hydrogen bonding are (1) a shifting of the stretching mode of the hydrogen-bonded hydrogen to lower energy, (2) an intensification of the shifted infrared absorption, and (3) a broadening of the absorption relative to the parent mode. This is exactly what is observed, including a $203-\mathrm{cm}^{-1}$ shift of the hydrogen stretching mode to lower energy (using the band positions in those matrices where nonrotating water was observed), and strongly indicates formation of a hydrogen-bonded complex. This is supported by the observation of a shift to higher energy of the $\mathrm{H}-\mathrm{O}-\mathrm{H}$ bending mode near $1600 \mathrm{~cm}^{-1}$, another vibrational signature of hydrogen bond formation. ${ }^{22}$ Finally, perturbation of the proton acceptor subunit occurs as well, although typically with smaller vibrational shifts. In the present study, the $\mathrm{P}=\mathrm{O}$ stretching mode was observed to shift $17 \mathrm{~cm}^{-1}$ to lower energy in the complex, from 1266 to $1249 \mathrm{~cm}^{-1}$. This supports hydrogen bond formation, and strongly indicates that the site of interaction on DMMP is the $\mathrm{P}=\mathrm{O}$ bond.
Several observations argue that the stoichiometry of the complex is $1: 1$. First, the product bands were observed at very high dilution, when the likelihood of formation of a higher complex (e.g., 2:1) during the matrix deposition process is very low. Previous matrix studies have demonstrated that matrices freeze very rapidly, and at low concentrations only the $1: 1$ complex is formed. Second, in the experiments employing $\mathrm{H}_{2}{ }^{18} \mathrm{O}$, residual $\mathrm{H}_{2}{ }^{16} \mathrm{O}$ was present as well. If the complex involved more than one water molecule, at least three isotopic bands would be expected, since a mixed isotopic ${ }^{16,18} \mathrm{O}$ species would be possible. However, only two bands were observed, suggesting the presence of a single $\mathrm{H}_{2} \mathrm{O}$ subunit in the complex. Third, if a higher complex formed, one would also expect to see some of the 1:1 complex, and the ratio of the two complexes would change as a function of sample concentration. Yet, the spectra clearly indicated formation of only a single product. Finally, the theoretical calculations described above predict that the 1:1 complex is stable and as shown in Table 2 (and discussed further below) the predicted vibrational shifts for the $1: 1$ complex are in very good agreement with the experimental shifts observed here. Taken together, the data strongly support formation of a 1:1 complex between $\mathrm{H}_{2} \mathrm{O}$ and DMMP, involving hydrogen bond formation between an $\mathrm{O}-\mathrm{H}$ bond on $\mathrm{H}_{2} \mathrm{O}$ and the $\mathrm{P}=\mathrm{O}$ on DMMP.

Band assignments are straightforward, based on the above arguments. The band at $3436 \mathrm{~cm}^{-1}$ is assigned to the hydrogenbonded $\mathrm{O}-\mathrm{H}$ stretch in the $1: 1$ complex, an assignment that is supported by the $10-\mathrm{cm}^{-1}$ shift to lower energy when $\mathrm{H}_{2}{ }^{18} \mathrm{O}$ was employed. This shift is exactly what is anticipated based on parent $\mathrm{H}_{2} \mathrm{O}$. This shift is also nearly identical with that calculated for an isolated harmonic $\mathrm{O}-\mathrm{H}$ oscillator. The band at $1633 \mathrm{~cm}^{-1}$ is assigned to the blue-shifted $\mathrm{H}_{2} \mathrm{O}$ bending mode, as anticipated. Unfortunately, this region was too congested in the mixed ${ }^{16} \mathrm{O},{ }^{18} \mathrm{O}$ experiments and an ${ }^{18} \mathrm{O}$ counterpart of this band could not be detected. Fortunately, this region can be resolved theoretically. There are approximately 10 normal vibrational modes in this region, mostly attributable to $\mathrm{C}-\mathrm{H}$ bending. As noted above, the product band at $1249 \mathrm{~cm}^{-1}$ is assigned to the $\mathrm{P}=\mathrm{O}$ stretch, shifted $17 \mathrm{~cm}^{-1}$ from the parent. Again, this shift is consistent with the calculated value. The remaining product bands were observed within a few wavenumbers of parent bands of DMMP, and are assigned to the analogous vibrational modes in the complex.

The MP2/6-31+G** level of theory has been identified previously in the literature as the minimum level of theory required to obtain reliable geometries of hydrogen-bonded complexes. $^{23}$ As noted, the calculated complex shifts and isotopic shifts at this level agree almost exactly with experimental values, particularly in the $\mathrm{P}=\mathrm{O}$ stretch, $\mathrm{H}_{2} \mathrm{O}$ bend, and $\mathrm{O}-\mathrm{H}$ stretch frequencies which are most affected by the formation of the hydrogen bond. Frequencies obtained for Conformer I of DMMP were used for calculating all complexation shifts, although differences in calculated spectra for Conformer I and Conformer II are minor. For example, use of the Conformer II parent band yields a shift in the $\mathrm{P}=\mathrm{O}$ stretch of $-15 \mathrm{~cm}^{-1}$ (rather than $-21 \mathrm{~cm}^{-1}$ ) also in excellent agreement with the experimental $\mathrm{P}=\mathrm{O}$ shift of $-17 \mathrm{~cm}^{-1}$. It should also be noted that the B3LYP/6-31G** level of theory results agree remarkably well with experimental shift values. Inclusion of anharmonic effects is expected to improve agreement with experiment still further. ${ }^{23,24}$ A more detailed listing of the calculated spectra is included in the Supporting Information. 
Differences in the DMMP: $\mathrm{H}_{2} \mathrm{O}$ complex structure between the different levels of theory are remarkably subtle, and are primarily evident in an $\sim 10^{\circ}$ variation in $\mathrm{CH}_{3}-\mathrm{P}-\mathrm{O}-\mathrm{CH}_{3}$ dihedral angles (e.g., $\mathrm{CH}_{3}-\mathrm{P}-\mathrm{O}-\mathrm{CH}_{3}$ dihedrals are $172^{\circ}$ and $134^{\circ}$ for the MP2/6-31+G** complex, but $168^{\circ}$ and $130^{\circ}$ at B3LYP/6-31G**, respectively). As we have noted previously, the energy landscape with respect to this dihedral is very complex in the parent DMMP molecule. Therefore it is not surprising to see significant variation in this dihedral value. There is also a marked difference in the orientation of the nonbonding water hydrogen (H19 in Figure 3) with the addition of the diffuse functions. Coordinates for the MP2/6-31+ $\mathrm{G}^{* *}$ complex are included in the Supporting Information. The hydrogen bond in the complex is roughly linear at all levels of theory, with only slight variations in the $\mathrm{O}-\mathrm{H}-\mathrm{O}$ angle $\left(160.5^{\circ}\right.$ at MP2/6-31+G**, $161.9^{\circ}$ at MP2/6-31G**, $161.4^{\circ}$ at B3LYP/ 6-31G**). The heavy atom-heavy atom $(\mathrm{O}-\mathrm{O})$ distance also falls within a very narrow range $\left(2.79 \AA\right.$ at $\mathrm{MP} 2 / 6-31+\mathrm{G}^{* *}$, $2.81 \AA$ at MP2/6-31G**, $2.78 \AA$ at B3LYP/6-31G**). It has been suggested ${ }^{25}$ that the $\mathrm{H}$-bond distance on the proton acceptor side of the bond (O3-H17 distance in Figure 3) is a more accurate descriptor of hydrogen bond strength. The O3-H17 distances obtained in the calculated structures $(1.85 \AA$ at MP2/ 6-31+G**, $1.87 \AA$ at MP2/6-31G**, $1.83 \AA$ at B3LYP/6$31 \mathrm{G}^{* *}$ ) fall solidly within the range of 1.56 to $1.97 \AA$ found by Espinosa et al. ${ }^{25}$ in their analysis of existing experimental data on a range of $\mathrm{O}-\mathrm{H} \cdots \mathrm{O}$ hydrogen-bonded systems. It has also been suggested ${ }^{26}$ that proton-shift NMR spectroscopy is a reliable tool for analysis of $\mathrm{OHO}$ hydrogen bonds, and this is left for future work.

\section{Conclusions}

The matrix isolation experiments conducted here demonstrate that $\mathrm{H}_{2} \mathrm{O}$ and DMMP form a stable, 1:1 hydrogen-bonded complex. Key vibrational modes were observed to shift upon hydrogen bond formation, with a direction and magnitude that agreed well with theoretical predictions. These results suggest that complexation between $\mathrm{H}_{2} \mathrm{O}$ and DMMP may be a key factor in the suppression of volatility of DMMP in humid air, as has been observed experimentally.

Acknowledgment. The authors gratefully acknowledge GeoCenters Subcontract No. 41486SM-sub Army in support of the experimental work.

Supporting Information Available: DMMP, $\mathrm{H}_{2} \mathrm{O}$, DMMP$\mathrm{H}_{2} \mathrm{O}$, DMMP- $\mathrm{H}_{2}{ }^{18} \mathrm{O}$ complex calculated geometries and harmonic frequencies (B3LYP/6-31G**, MP2/6-31+G**, and MP2/6-31G** level of theory). This material is available free of charge via the Internet at http://pubs.acs.org.

\section{References and Notes}

(1) Tevault, D. E.; Buchanan, J. H.; Buettner, L. C. Volatility of Dimethyl Methylphosphonate (DMMP) in Humid Air; ECBC-TR-305, June, 2003.

(2) Tevault, D. E.; Buchanan, J. H.; Buettner, L. C. Volatility of Dimethyl Methylphosphonate (DMMP) in Humid Air; Proceedings of the Fifteenth Symposium On Thermophysical Properties, Boulder, CO, June 22-27, 2003.

(3) Craddock, S.; Hinchliffe, A. Matrix Isolation; Cambridge University Press: Cambridge, 1975.

(4) Hallam, H. E. Vibrational Spectroscopy of Trapped Species; John Wiley: New York, 1973.

(5) Andrews, L.; Moskovitz, M., Eds. Chemistry and Physics of Matrix Isolated Species; Elsevier Science Publishers: Amsterdam, THe Netherlands, 1989.

(6) See, for example: Barnes, A. J. J. Mol. Struct. 1983, 100, 259

(7) Ault, B. S.; Pimentel, G. C. J. Phys. Chem. 1973, 77, 57.

(8) Sankaran, K.; Vidya, V.; Viswanathan, K. S.; George, L.; Singh, S. J. Phys. Chem. A 1998, 102, 2944.

(9) Zhang, X. K.; Lewars, E. G.; March, R. E.; Parnis, J. M. J. Phys. Chem. 1993, 97, 4320.

(10) Goebel, J.; Ault, B. S.; Del Bene, J. E. J. Phys. Chem. A 2000, 104, 2033-2037.

(11) Goebel, J.; Ault, B. S.; Del Bene, J. E. J. Phys. Chem. A 2001, $105,6430-6435$.

(12) Goebel, J.; Ault, B. S.; Del Bene, J. E. J. Phys. Chem. A 2001, $105,11365-11370$

(13) Goebel, J. R.; Antle, K. A.; Ault, B. S.; Del Bene, J. E. J. Phys. Chem. A 2002, 106, 6406-6414.

(14) Ault, B. S. J. Am. Chem. Soc. 1978, 100, 2426

(15) Frisch, M. J.; Trucks, G. W.; Schlegel, H. B.; Scuseria, G. E.; Robb M. A.; Cheeseman, J. R.; Montgomery, J. A., Jr.; Vreven, T.; Kudin, K. N.; Burant, J. C.; Millam, J. M.; Iyengar, S. S.; Tomasi, J.; Barone, V.; Mennucci, B.; Cossi, M.; Scalmani, G.; Rega, N.; Petersson, G. A.; Nakatsuji, H.; Hada, M.; Ehara, M.; Toyota, K.; Fukuda, R.; Hasegawa, J.; Ishida, M.; Nakajima, T.; Honda, Y.; Kitao, O.; Nakai, H.; Klene, M.; Li, X.; Knox, J. E.; Hratchian, H. P.; Cross, J. B.; Adamo, C.; Jaramillo, J.; Gomperts, R.; Stratmann, R. E.; Yazyev, O.; Austin, A. J.; Cammi, R.; Pomelli, C.; Ochterski, J. W.; Ayala, P. Y.; Morokuma, K.; Voth, G. A.; Salvador, P.; Dannenberg, J. J.; Zakrzewski, V. G.; Dapprich, S.; Daniels, A. D.; Strain, M. C.; Farkas, O.; Malick, D. K.; Rabuck, A. D.; Raghavachari, K.; Foresman, J. B.; Ortiz, J. V.; Cui, Q.; Baboul, A. G.; Clifford, S.; Cioslowski, J.; Stefanov, B. B.; Liu, G.; Liashenko, A.; Piskorz, P.; Komaromi, I.; Martin, R. L.; Fox, D. J.; Keith, T.; Al-Laham, M. A.; Peng, C. Y.; Nanayakkara, A.; Challacombe, M.; Gill, P. M. W.; Johnson, B.; Chen, W.; Wong, M. W.; Gonzalez, C.; Pople, J. A. Gaussian 03; Gaussian, Inc.: Pittsburgh, PA, 2003.

(16) Ayers, G. P.; Pullin, D. E. Spectrochim. Acta 1976, 32A, 1629

(17) Ayers, G. P.; Pullin, D. E. Spectrochim. Acta 1976, 32A, 1689

(18) Barnes, A. J.; Lomax, S.; Van der Veken, B. J. J. Mol. Struct. 1983, 99, 137.

(19) White, W. E., Technical Report ECBC-TR-265, 2002; Edgewood Chemical Biological Center, RDECOM, U.S. Army.

(20) Suenram, R. D.; Lovas, F. J.; Plusquellic, D. F.; Lesarri, A.; Kawashima, Y.; Jensen, J. O.; Samuels, A. C. J. Mol. Spectrosc. 2002, 211,110 .

(21) Vishnyakov, A.; Neimark, A. V. J. Phys. Chem. A 2004, 108, 1435.

(22) Pimentel, G. C.; McClellan, A. The Hydrogen Bond; W. H. Freeman, Co.: San Francisco, CA, 1960.

(23) Del Bene, J. E.; Jordan, M. J. T. J. Mol. Struct. (THEOCHEM) 2001, 573, 11-23.

(24) Barone, V. J. Phys. Chem A 2004, 108, 4146-4150.

(25) Espinosa, E.; Molins, E.; Lecomte, C. Chem. Phys. Lett. 1998, 285, $170-173$.

(26) Emmler, Th.; Gieschler, S.; Limbach, H. H.; Buntkowsky, G. J. Mol. Struct. 2004, 700, 29-38. 